\title{
TIMP-1 as well as Microvessel Invasion and High Nuclear Grade Is a Significant Determinant Factor for Extension of Tumor Diameter in Localized RCC
}

\author{
Nozomu Kawata, Kenya Yamaguchi, Tomohiro Igarashi, and Satoru Takahashi \\ Department of Urology, Nihon University School of Medicine, 1-6 Kanda-Surugadai, Chiyoda-ku, Tokyo, Japan \\ Correspondence should be addressed to Nozomu Kawata; kawata.nozomu@nihon-u.ac.jp
}

Received 28 May 2015; Revised 22 October 2015; Accepted 25 October 2015

Academic Editor: James L. Mulshine

Copyright (c) 2016 Nozomu Kawata et al. This is an open access article distributed under the Creative Commons Attribution License, which permits unrestricted use, distribution, and reproduction in any medium, provided the original work is properly cited.

\begin{abstract}
Objectives. To clarify what kind of pathological factor is necessary for the extension of tumor diameter in localized RCC, we studied localized RCC patients. Methods. We retrospectively reviewed medical records of 237 RCC patients in our institute who underwent nephrectomy. We performed immune histological analysis of MMP-2, MMP-9, TIMP-1, TIMP-2, and MT-MMP-1 for all samples. Results. Among the clinicopathological factors, multivariate analysis revealed nuclear grade; TIMP-2 and MT-MMP-1 were independent prognostic factors of localized RCC (risk ratio 1.50, $p=0.037$, risk ratio 1.12, $p=0.008$, and risk ratio 1.84, $p=0.045$, resp.). By the multiple logistic regression analysis among pTla versus pT1b, TIMP-1 was an independent factor (risk ratio 3.30, $p=0.010$ ) whereas all pT1 versus pT2a and all pT1 + pT2a versus pT2b high nuclear grade (risk ratio $5.15, p=0.0015$ ) and Micro vessel invasion (MVI, risk ratio 3.08, $p=0.002$ ) were independent factors. For all pT1 + pT2a versus pT2b, nuclear grade (risk ratio 3.39, $p=0.020$ ) and MVI (risk ratio 2.91, $p=0.018$ ) were independent factors. Conclusion. Higher expression of TIMP-1 is necessary for advancement tumor diameter from pTla to pT1b, and a process of tumor diameter extension beyond pT1 and pT2a category needs presence of MVI and high nuclear grade.
\end{abstract}

\section{Introduction}

Recently, Frank et al. [1] and Klatte et al. [2] proposed a subclassification of T2 RCC into pT2a and pT2b according to tumor diameter with a cutoff of $10 \mathrm{~cm}$.

Based on their reports, the 7th edition of TNM classification [3], threshold value between T1 and T2 RCC was divided into T2a (up to $10 \mathrm{~cm}$ ) and T2b (more than $10 \mathrm{~cm}$ ) [3]. Lee et al. [4] reported that local control may be achieved in surgical management of contemporary patients with RCC of $4 \mathrm{~cm}$ or less either by radical or nephron sparing surgery, and, in addition, local recurrence rate after nephron sparing surgery was $0-12 \%$. The rate decreases to $0 \%$ to $3 \%$ for microscopically organ confined disease and $0 \%$ to $5 \%$ for small renal tumors [5]. It is well known that renal cell carcinoma with a diameter of more than $10 \mathrm{~cm}$ has high potential to cause distant metastasis and generally recommended surgical procedure is radical nephrectomy [1].
Previously, we reported that systemic symptoms of RCC have a strong significant relationship with the expression of matrix metalloproteinase 9 (MMP-9) [6]. It is well known that both MMPs (matrix metalloproteinases) and TIMPs (tissue inhibitors of metalloproteinases) play an important role in the progression of RCC. However, there are no reports examining the relationships among tumor diameter and MMPs and TIMPs. To clarify what kind of clinicopathological feature is necessary for extension of the tumor diameter, we studied localized RCC patients.

\section{Material and Method}

Between January 1988 and December 2003, a total of 237 patients had underwent radical nephrectomy for localized renal cell carcinoma at Nihon University Itabashi or Surugadai Hospital. Patients consisted of 176 males and 61 females, mean age of $60(33-83)$ and 58 (25-82), respectively. 


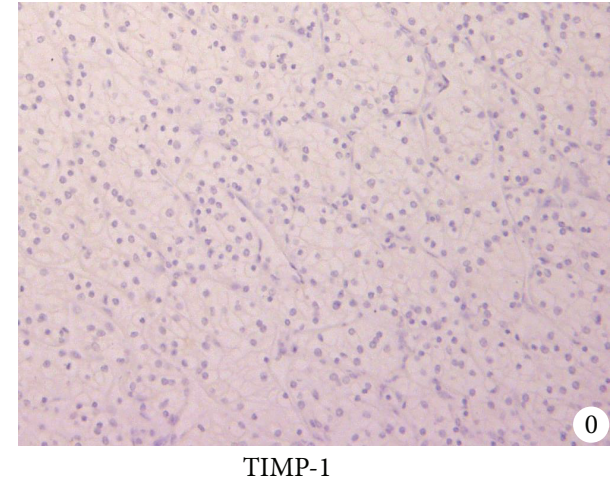

(a)

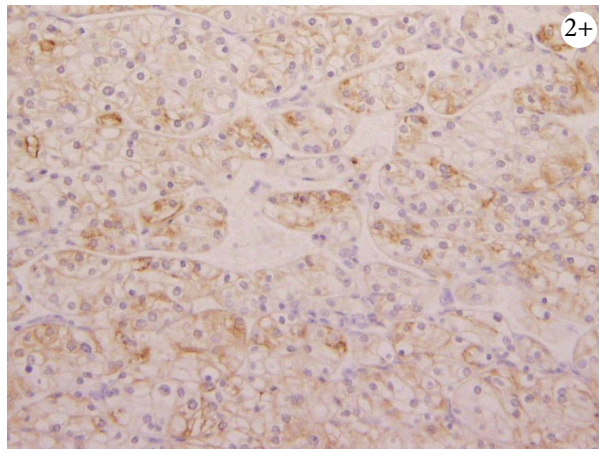

TIMP-1

(c)

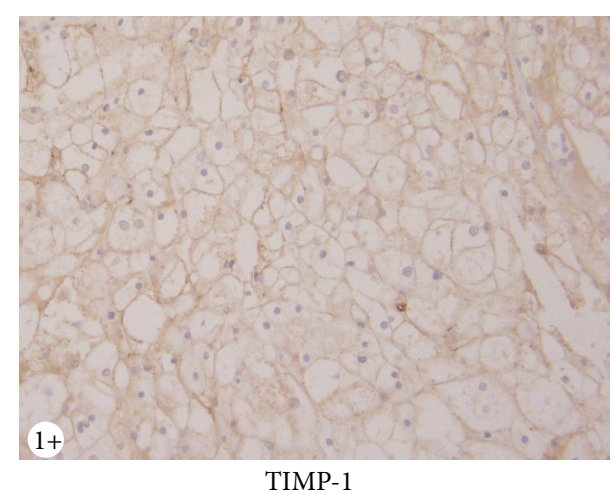

(b)

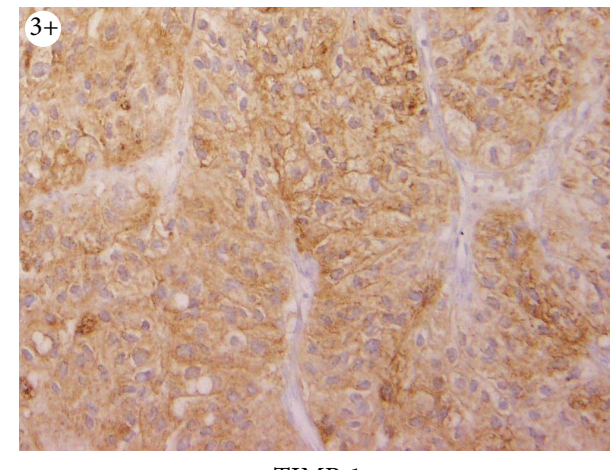

TIMP-1

(d)

FIGURE 1: 0 indicates the absence of immune staining or faint membranous staining of rare tumor cells; $1+$ indicates membranous staining in most tumor cells; $2+$ indicates diffuse membranous and/or cytoplasmic staining in groups of tumor cells; and 3+ indicates significant cytoplasmic staining in most tumor cells. For the evaluation of immune histochemical staining, intensities of $2+$ and $3+$ were considered strong expressions of each protein.

The average postoperative follow-up period was $61 \pm 3.6$ months. All patients underwent preoperative chest and abdominal contrast enhanced CT, and bone scan if required. Pathological stages were determined according to the TNM classification of malignant tumors [3].

Tumors were classified as pT1a, pT1b, pT2a, and pT2b in $94(40 \%), 74(31 \%), 43(18 \%)$, and $26(11 \%)$ cases, respectively.

The nuclear grade of RCC was determined using the criteria proposed by Fuhrman et al. [7]. Since several studies found no significant difference in survival results between patients with Grade 1 versus 2 tumors and those with Grade 3 versus 4 tumors [8], a total of 237 patients were divided into two groups according to nuclear grade: a low nuclear grade group (Grades 1 and 2, 190 patients) and a high nuclear grade group (Grades 3 and 4, 47 patients).

Microvessel invasion (MVI) was defined as a tumor infiltration locally through the intact vessel wall including the endothelium, leading to free extension of cancer cells into the lumen [9].

The maximum tumor diameter (MTD) was confirmed by pathological specimens. We applied immunohistochemistry on the cut surface of tumor with no necrosis nor intratumoral hemorrhage.
The immunohistochemical study for MMP-2, MMP9, TIMP-1, TIMP-2, and MT-MMP-1 was performed by methods we previously reported [6]. For evaluation of immunohistochemical staining, staining intensities of $2+$ and $3+$ were considered strong expressions of each protein (Figure 1) [6].

Cancer-specific survival (CSS) was defined as the interval from initial surgery to death and was calculated by the method of Kaplan and Meier. Statistical significance was determined by the log-rank test. Cox multivariate analysis was performed to determine any independent predictive values.

To determine the relationships between $\mathrm{T}$ categories and 8 pathological features of RCC (histopathological type, nuclear grade, MVI, MMP-2, MMP-9, TIMP-1, TIMP-2, and MT-MMP-1), we compared the quantitative results using a multiple logistic regression analysis. Intergroup differences were considered statistically significant at $p<0.05$. All analyses were performed using JMP4.0 (SAS Institute, Cory, NC, USA).

The study using these specimens was performed under the approval of Nihon University School of Medicine Ethics Board (IRB number 106-1). 
TABLE 1: Predictors of localized 237 RCC cases postoperative specific mortality.

\begin{tabular}{|c|c|c|c|c|}
\hline \multirow{2}{*}{ Categories } & \multicolumn{2}{|c|}{ Univariate analysis } & \multicolumn{2}{|c|}{ Multivariate analysis } \\
\hline & Hazard ratio $(95 \% \mathrm{CI})$ & $p$ value & Hazard ratio $(95 \% \mathrm{CI})$ & $p$ value \\
\hline $\begin{array}{l}\text { pTla versus pTlb } \\
94 \text { versus } 74\end{array}$ & $2.38(1.02-5.55)$ & 0.046 & $1.35(0.96-1.88)$ & 0.086 \\
\hline $\begin{array}{l}\text { p T1a versus pT2a } \\
94 \text { versus } 43\end{array}$ & $1.40(0.49-4.0)$ & 0.53 & $1.07(0.93-1.42)$ & 0.74 \\
\hline $\begin{array}{l}\text { pT1a versus pT2b } \\
94 \text { versus } 26\end{array}$ & $4.0(1.51-1.020)$ & 0.005 & $1.09(0.66-1.85)$ & 0.71 \\
\hline $\begin{array}{l}\text { Clear versus nonclear } \\
190 \text { versus } 47\end{array}$ & $2.05(1.00-4.019)$ & 0.048 & $1.12(0.77-1.65)$ & 0.53 \\
\hline $\begin{array}{l}\text { Nuclear Grades } 1 \text { and } 2 \text { versus } 3 \\
\text { and } 4 \\
190 \text { versus } 47\end{array}$ & $1.79(1.76-6.84)$ & $<0.001$ & $1.50(1.03-2.22)$ & 0.037 \\
\hline $\begin{array}{l}\text { MVI }(-) \text { versus }(+) \\
154 \text { versus } 83\end{array}$ & $1.95(0.92-2.94)$ & 0.025 & $1.04(0.33-1.21)$ & 0.94 \\
\hline $\begin{array}{l}\text { MMP- } 2 \text { weak versus strong } \\
82 \text { versus } 155\end{array}$ & $3.69(1.43-9.52)$ & 0.0069 & $1.26(0.30-5.23)$ & 0.74 \\
\hline $\begin{array}{l}\text { MMP-9 weak versus strong } \\
181 \text { versus } 56\end{array}$ & $4.29(2.17-8.16)$ & $<0.0001$ & $2.88(0.92-2.94)$ & 0.75 \\
\hline $\begin{array}{l}\text { TIMP-1 weak versus strong } \\
42 \text { versus } 195 \\
\end{array}$ & $2.52(0.77-8.26)$ & 0.12 & $1.014(0.709-1.45)$ & 0.34 \\
\hline $\begin{array}{l}\text { TIMP-2 weak versus strong } \\
201 \text { versus } 36\end{array}$ & $2.07(0.99-4.31)$ & 0.052 & $1.12(1.36-3.29)$ & 0.020 \\
\hline $\begin{array}{l}\text { MT-MMP-1 weak versus strong } \\
194 \text { versus } 43\end{array}$ & $3.44(1.73-6.84)$ & 0.005 & $1.84(1.21-2.82)$ & 0.045 \\
\hline
\end{tabular}

\section{Results}

Among the tumors, 194 (82\%) were conventional clear cell carcinomas, 42 (17\%) were papillary carcinomas, and $1(0.3 \%)$ was a chromophobe carcinoma. Tumors were classified as pTla, pT1b, pT2a, and pT2b in 94 (40\%), 74 (31\%), 43 (18\%), and $26(11 \%)$ cases, respectively. The median tumor diameter was $50 \mathrm{~mm}(15-250 \mathrm{~mm})$. Among a total of 237 patients, 190 were classified as having a low nuclear grade (Grades 1 and 2), whereas 47 as having a high nuclear grade (Grades 3 and 4).

The cancer-specific 10-year survival rates were $88.8 \%$, $69.5 \%, 80.3 \%$, and $50.0 \%$ for pTla, pT1b, pT2a, and pT2b, respectively (Figure 2, $p<0.001$ ).

With respect to the cancer-specific mortality, the univariate analysis showed no significance for pTla versus pT2a and TIMP-1 and TIMP-2 as a determinant factor, while the remaining 8 factors were significant factors of postoperative specific mortality of 247 patients (Table 1). By the multivariate analysis of clinicopathological factors, nuclear grade, TIMP2, and MT-MMP-1 were independent prognostic factors (risk ratio $1.50, p=0.037$, risk ratio $1.12, p=0.02$, and risk ratio $1.84, p=0.045$, resp.) (Table 1 ).

We compared the clinicopathological factors in three categories: pT1a versus pT1b, all pT1 versus pT2a, and all pT1 + pT2a versus pT2b. By the Cox multivariate analysis (Table 2), among the pTla versus pT1b group, TIMP-1 was an independent factor (risk ratio 3.30, $p=0.010$ ). For $\mathrm{pT} 1$ versus pT2a, both nuclear grade (risk ratio 5.15, $p=0.0015$ ) and MVI (risk ratio 3.08, $p=0.002$ ) were independent factors. For the remaining pT1 + pT2a versus pT2b, both nuclear

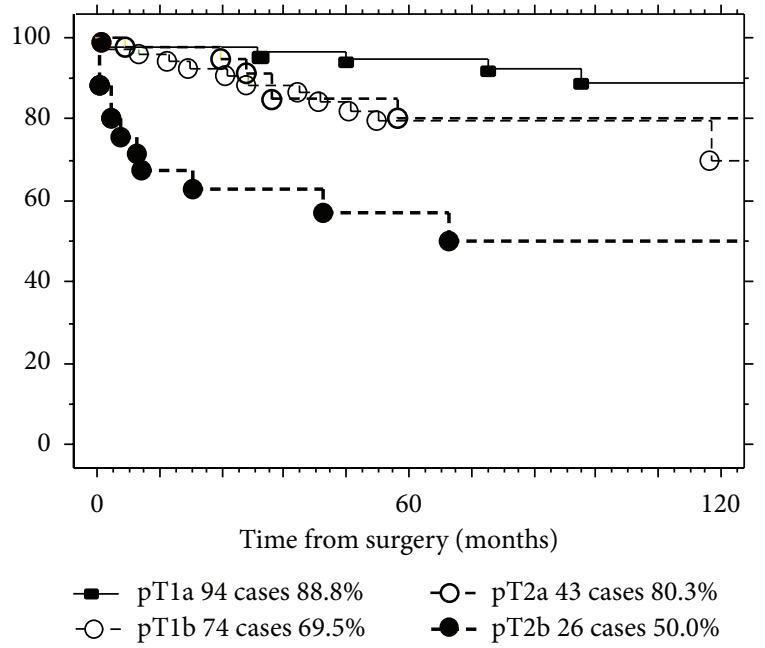

FIGURE 2: Cancer-specific survival rate according to the pT category.

grade (risk ratio 3.39, $p=0.020$ ) and MVI (risk ratio 2.91, $p=0.018)$ were significant factors.

\section{Discussion}

Once MMPs are stimulated, they are susceptible to prohibition by the general serum proteinase inhibitor $\alpha 2$ macroglobulin and by a family of specific tissue inhibitors (TIMPs). On the other hand, TIMPs have been frequently 
TABLE 2: Correlation between pT category and pathological features with localized 237 RCC cases.

\begin{tabular}{|c|c|c|c|}
\hline & $\begin{array}{c}\text { pTla versus pTlb } \\
\text { Odds ratio (95\% CI) } p \text { value } \\
94 \text { versus } 74 \\
\text { Cases of each category }\end{array}$ & $\begin{array}{c}\text { pTla and pT1b versus pT2a } \\
\text { Odds ratio (95\% CI) p value } \\
168 \text { versus } 43 \\
\text { Cases of each category }\end{array}$ & $\begin{array}{c}\text { pTla, pT1b, and pT2a versus pT2b } \\
\text { Odds ratio ( } 95 \% \text { CI) p value } \\
211 \text { versus } 26 \\
\text { Cases of each category }\end{array}$ \\
\hline Cell type & $2.43(0.85-6.89) 0.09$ & $2.28(0.76-6.82) 0.13$ & $2.32(0.84-6.36) 0.10$ \\
\hline Clear versus others & 139 versus 29 & 175 versus 36 & 190 versus 47 \\
\hline Nuclear grade & $1.79(0.57-5.56) 0.31$ & $5.15(1.87-14.2) 0.0015$ & $3.39(1.20-9.58) 0.020$ \\
\hline Low versus high & 147 versus 21 & 176 versus 35 & 190 versus 47 \\
\hline MVI & $1.95(0.92-4.16) 0.08$ & $3.08(1.47-6.48) 0.002$ & $2.91(1.19-7.11) 0.018$ \\
\hline$(-)$ versus $(+)$ & 123 versus 45 & 144 versus 67 & 154 versus 83 \\
\hline MMP-2 & $1.14(0.55-2.36) 0.71$ & $2.13(0.90-5.0) 0.84$ & $1.24(0.41-3.70) 0.70$ \\
\hline Weak versus strong & 60 versus 108 & 76 versus 135 & 82 versus 156 \\
\hline MMP-9 & $1.79(0.65-4.90) 0.205$ & $1.47(0.55-3.94) 0.43$ & $1.31(0.40-4.21) 0.64$ \\
\hline Weak versus strong & 134 versus 34 & 163 versus 48 & 181 versus 56 \\
\hline TIMP-1 & $3.30(1.32-8.26) 0.010$ & $1.18(0.43-3.26) 0.74$ & $1.59(0.49-5.10) 0.42$ \\
\hline Weak versus strong & 31 versus 137 & 37 versus 174 & 42 versus 195 \\
\hline TIMP-2 & $1.41(0.48-4.13) 0.53$ & $2.14(0.65-6.99) 0.84$ & 3.03 (0.71-12.98) 0.13 \\
\hline Weak versus strong & 142 versus 26 & 178 versus 33 & 201 versus 36 \\
\hline MT-MMP-1 & $1.93(0.65-5.71) 0.096$ & $2.28(0.76-3.50) 0.15$ & $1.98(0.60-6.54) 0.26$ \\
\hline Weak versus strong & 144 versus 26 & 176 versus 35 & 194 versus 43 \\
\hline
\end{tabular}

MVI: microvascular invasion.

reported that they may be multifunctional, because of additional effects on cell growth and apoptosis. These activities appear to be distinct from their MMP inhibitory capabilities in some cases [10].

Previously, we reported that high expression levels of MMP-9 were associated with poor prognosis of RCC [11]. Basically, TIMPs are known to inhibit MMP activity by forming a complex with active MMPs and are believed to be specific for enzymes of this family, such as TIMP-1 with MMP-9 and TIMP-2 with MMP-2 [12]. Members of the TIMP family have also been associated with cancer. In several cases, malignant tumors have elevated TIMP levels rather than decreased levels [12].

MMP-9 has a significant relationship with high nuclear grade RCC and was found to be an independent prognosticator by multivariate analysis. Furthermore, nuclear grade and TIMP-2 were independent prognostic factors among the incidental RCC patients [13].

With regard to MVI, Ishimura reported that MVI is not a significant prognostic factor in localized RCC patients; on the other hand, it is the only significant prognostic factor of disease free recurrence after radical operation for patients with pT1 and pT2 disease [14]. Additionally, Dall'Oglio et al. showed a significant relationship between MVI and clinical stage. In 95 tumors below $4 \mathrm{~cm}$ in diameter, MVI was detected in $11(12 \%)$, while in 74 tumors of $4.1-7 \mathrm{~cm}$, MVI was detected in $20(27 \%)$, and in 61 of over $7 \mathrm{~cm}, 28$ (48\%) had MVI [15].

Previously we reported that cancer-specific 5-year survival was $45.0 \%$ for patients with high nuclear grade tumor (Grade 3.4) and $83.3 \%$ for patients with low nuclear grade tumor (Grade 1.2) $(p<0.001)$ [16]. Zhang et al. reported a significant correlation between tumor size and nuclear grade.
By their report, tumor diameters of G1, G2, and G3 tumors were significantly different $(3.27 \pm 1.46 \mathrm{~cm}, 4.87 \pm 2.23 \mathrm{~cm}$, and $7.39 \pm 3.11 \mathrm{~cm}, p<0.05)$. Tumors with larger diameter were prone to have higher nuclear grade. These results were consistent with ours [17].

\section{Conclusion}

In conclusion, higher expression of TIMP-1 is necessary for advancement of tumor diameter from pTla to pTlb, and a process of tumor diameter extension beyond pT1 category needs the presence of MVI and high nuclear grade.

\section{Conflict of Interests}

The authors declare that there is no conflict of interests regarding the publication of this paper.

\section{References}

[1] I. Frank, M. L. Blute, B. C. Leibovich et al., "pT2 classification for renal cell carcinoma. Can its accuracy be improved?" Journal of Urology, vol. 173, no. 2, pp. 380-384, 2005.

[2] T. Klatte, J.-J. Patard, R. H. Goel et al., "Prognostic impact of tumor size on pT2 renal cell carcinoma: aninternational multicenter experience," Journal of Urology, vol. 178, no. 1, pp. 35-40, 2007.

[3] L. H. Sobin, M. K. Gospondarowics, and Ch. Wittekind, TNM Classification of Malignant Tumours, Wiley-Blackwell, New York, NY, USA, 7th edition, 2009.

[4] C. T. Lee, J. Katz, W. Shi, H. T. Thaler, V. E. Reuter, and P. Russo, "Surgical management of renal tumors $4 \mathrm{~cm}$. Or less in 
a contemporary cohort," The Journal of Urology, vol. 163, no. 3, pp. 730-736, 2000.

[5] S. E. Lerner, C. A. Hawkins, M. L. Blute et al., "Disease outcome in patients with low stage renal cell carcinoma treated with nephron sparing or radical surgery," The Journal of Urology, vol. 155, no. 6, pp. 1868-1873, 1996.

[6] N. Kawata, Y. Nagane, T. Igarashi et al., "Strong significant correlation between MMP-9 and systemic symptoms in patients with localized renal cell carcinoma," Urology, vol. 68, no. 3, pp. 523-527, 2006.

[7] S. A. Fuhrman, L. C. Lasky, and C. Limas, "Prognostic significance of morphologic parameters in renal cell carcinoma," American Journal of Surgical Pathology, vol. 6, no. 7, pp. 655663, 1982.

[8] L. J. Medeiros, A. B. Gelb, and L. M. Weiss, "Renal cell carcinoma: prognostic significance of morphologic parameters in 121 cases," Cancer, vol. 61, no. 8, pp. 1639-1651, 1988.

[9] H. Lang, V. Lindner, C. Saussine, D. Havel, F. Faure, and D. Jacqmin, "Microscopic venous invasion: a prognostic factor in renal cell carcinoma," European Urology, vol. 38, no. 5, pp. 600$605,2000$.

[10] A. F. Chambers and L. M. Matrisian, "Changing views of the role of matrix metalloproteinases in metastasis," Journal of the National Cancer Institute, vol. 89, no. 17, pp. 1260-1270, 1997.

[11] A. Sato, H. Nagase, D. Obinata et al., "Inhibition of MMP-9 using a pyrrole-imidazole polyamide reduces cell invasion in renal cell carcinoma," International Journal of Oncology, vol. 43, no. 5, pp. 1441-1446, 2013.

[12] D. J. Grignon, W. Sakr, M. Toth et al., "High levels of tissue inhibitor of metalloproteinase-2 (TIMP-2) expression are associated with poor outcome in invasive bladder cancer," Cancer Research, vol. 56, no. 7, pp. 1654-1659, 1996.

[13] N. Kawata, Y. Nagane, H. Hirakata et al., "Significant relationship of matrix metalloproteinase 9 with nuclear grade and prognostic impact of tissue inhibitor of metalloproteinase 2 for incidental clear cell renal cell carcinoma," Urology, vol. 69, no. 6, pp. 1049-1053, 2007.

[14] T. Ishimura, I. Sakai, I. Hara, H. Eto, and H. Miyake, "Microscopic venous invasion in renal cell carcinoma as a predictor of recurrence after radical surgery," International Journal of Urology, vol. 11, no. 5, pp. 264-268, 2004.

[15] M. F. Dall'Oglio, A. A. Antunes, Á. S. Sarkis et al., "Microvascular tumour invasion in renal cell carcinoma: the most important prognostic factor," BJU International, vol. 100, no. 3, pp. 552-555, 2007.

[16] N. Kawata, K. Yamaguchi, H. Hirakata, T. Hachiya, T. Yoshida, and Y. Takimoto, "Immunosuppressive acidic protein detects high nuclear grade localized renal cell carcinoma," Urology, vol. 66, no. 4, pp. 736-740, 2005.

[17] C. Zhang, X. Li, H. Hao, W. Yu, Z. He, and L. Zhou, "The correlation between size of renal cell carcinoma and its histopathological characteristics: a single center study of 1867 renal cell carcinoma cases," BJU International, vol. 110, no. 11 B, pp. E481-E485, 2012. 


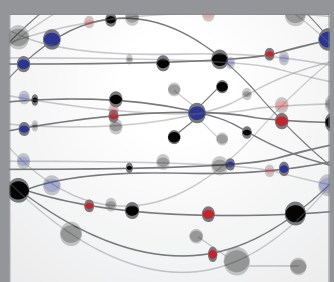

The Scientific World Journal
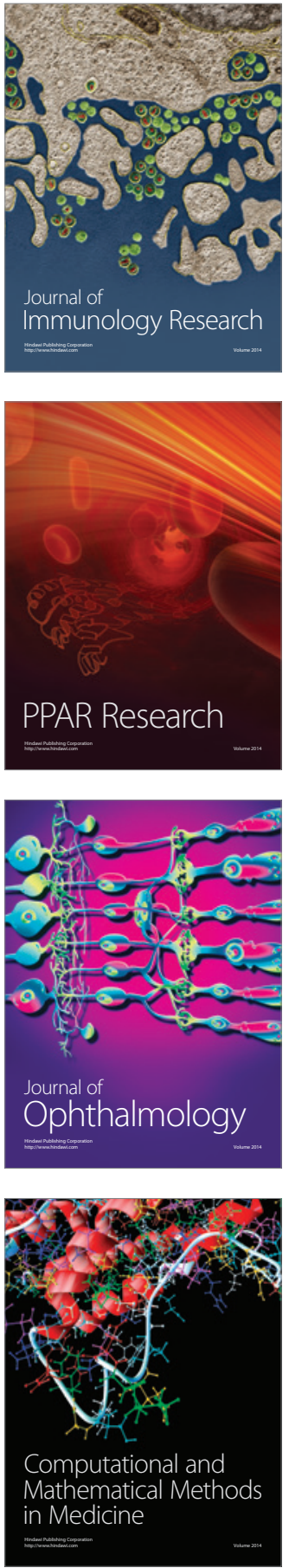

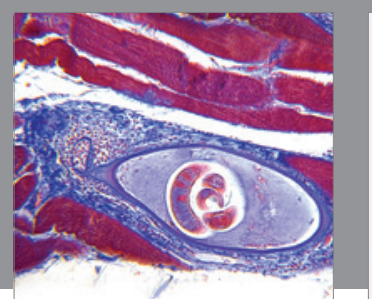

Gastroenterology Research and Practice

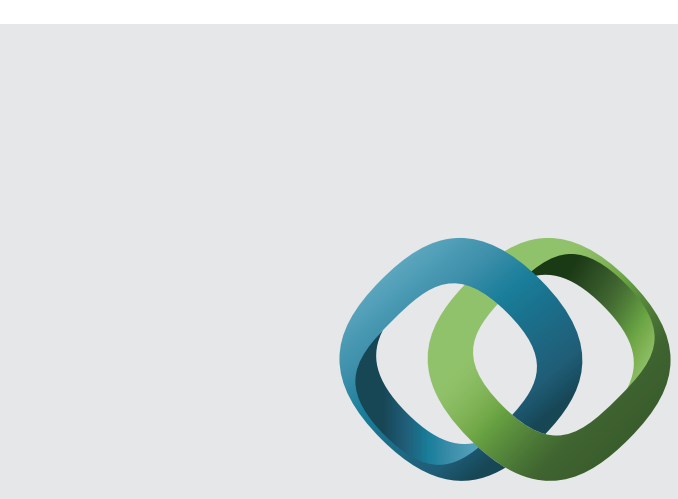

\section{Hindawi}

Submit your manuscripts at

http://www.hindawi.com
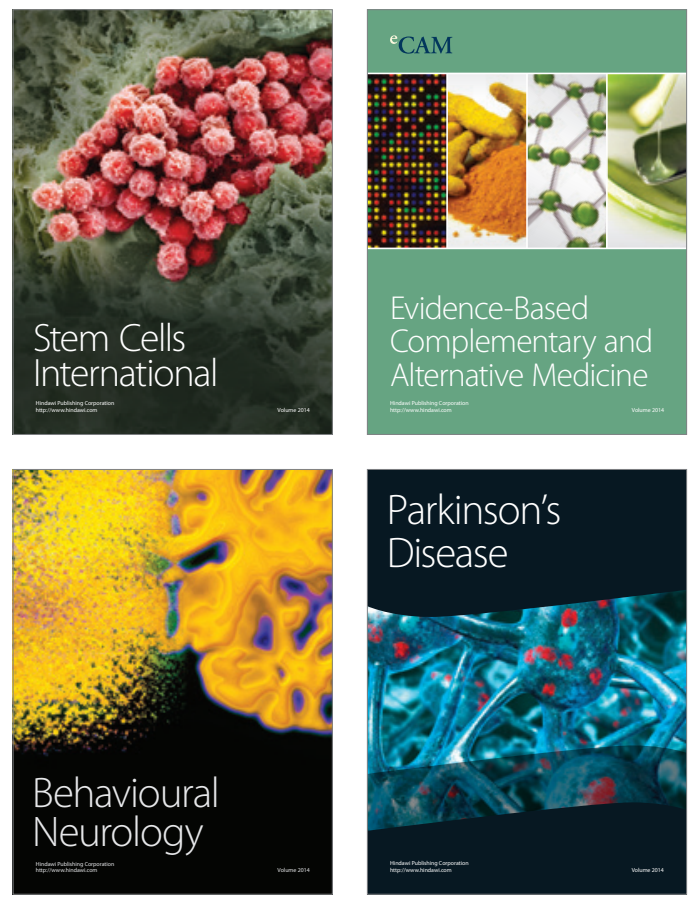
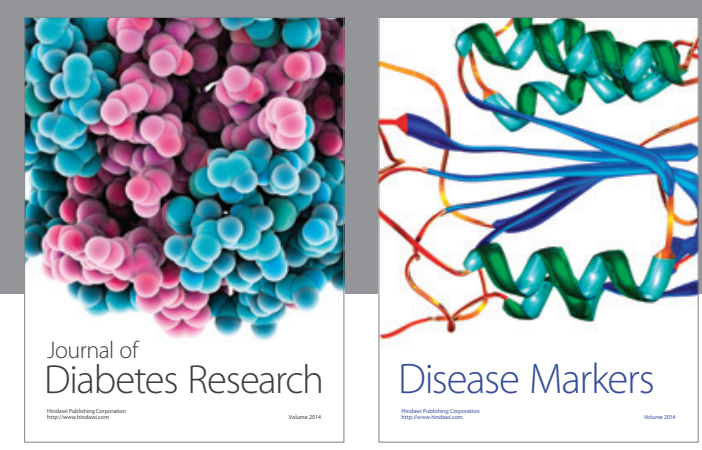

Disease Markers
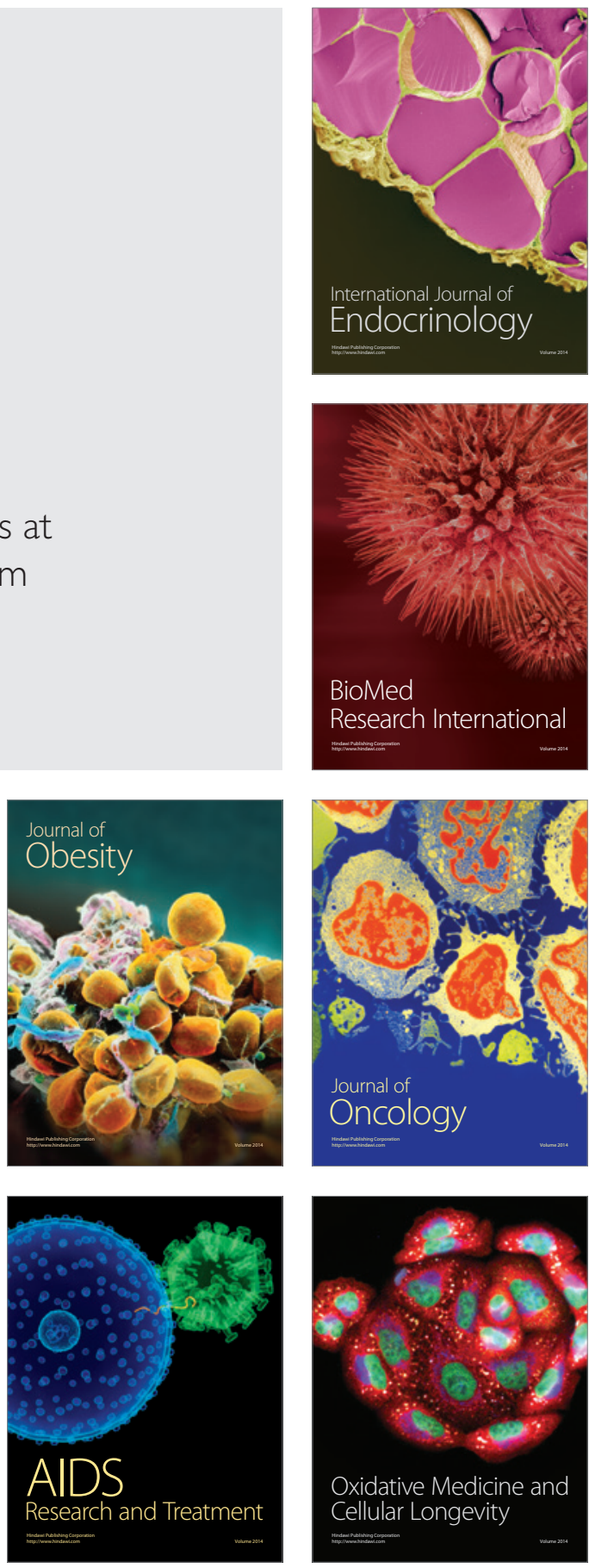